\title{
Monitoring spit development in Pomene, southern Mozambique, using Landsat data
}

\author{
E. A. Massuanganhe ${ }^{1} \&$ W. Arnberg $^{2}$ \\ ${ }^{1}$ Department of Geology, Faculty of Science, \\ Eduardo Mondlane University, Mozambique \\ ${ }^{2}$ Department of Physical Geography and Quaternary Geology, \\ Stockholm University, Sweden
}

\begin{abstract}
Coastal dunes, estuary, mangrove, and sand beach outlining a spit characterize Pomene on the southern coast of Mozambique. The spit is of interest for tourists and susceptible to coastal processes. Thus, four Landsat TM/ETM+ images dated 1984, 1989, 2001 and 2007 were used to monitor the geomorphologic change as well as to find the pattern of spit development spatially and temporally. From each Landsat image we extracted land and water (outlining the spit) by grouping 30 spectral classes from unsupervised ISO DATA classification using red, nearinfrared (NIR) and short-wavelength infrared (SWIR) spectral bands. Geographic Information System (GIS) software was used to process and present the final maps. Cross-classification was carried out to show the spatial difference between the dates. The results show a growth of the spit towards NNW and erosion at the Indian Ocean side, suggesting a longshore drift process in this area. The spit is becoming narrow and threatening its shape in the short term. The longshore currents caused by prevailing SSE winds, and offshore winds, are the main causes of the spit development.
\end{abstract}

Keywords: monitoring spit, coastal erosion, shoreline, southern Mozambique, coastal processes, estuary, Pomene.

\section{Introduction}

Located in Southern Mozambique, Pomene is known for its long beaches attracting tourists to the area bringing income to the country and to the people living nearby. Like many places in the Mozambican coastal zone, Pomene faces 
the Indian Ocean and is exposed to change due to coastal processes. In the area there are some tourist establishments operating, some of them threatened by erosion. Erosion is one of the largest problems in the coastal areas of Mozambique and, according to many people, human activity is the main driving factor. As there is an interest in developing the area, knowledge of the coastal processes is needed.

Most unpublished studies of coastal erosion done in Mozambique are limited to the description of erosion in a certain area, instead of explaining its causes. However, Cooper and Pilkey [1] and Armitage et al [2] studied coastal processes and evolution of barrier islands of southern Mozambique, pointing out to the Pleistocene spit progradation and dune deposition during sea level highstand as the model of it evolution. Armitage et al [2] applied this evolution model to the Mozambican coastal plain. Chemane et al [3] report vulnerability of coastal resource due to climate change in Mozambique, calling for Integrated Coastal Zone Management (ICZM). The Ministry for the Coordination of Environmental Affairs (MICOA) is responsible for study and control of the environmental and coastal hazards in Mozambique through the "Center for Sustainable Development of Coastal Zone" located in the city of Xai-Xai. The centre provides guidelines for studies of coastal processes and implementation of coastal management.

The study of coastal processes is essential for the understanding of coastal geomorphology and they are a foundation for coastal management. Waves, winds, tides, tidal currents and catastrophic events are the main agents shaping the landforms and driving forces of erosion and accretion. However, there is a lack of knowledge concerning the pattern of nearshore currents and waves characteristics in southern Mozambique. Ramsay [4] points out the predominance of SSE winds in southern Africa (including Pomene) as cause of waves and longshore currents toward north, opposing the southward offshore Mozambique Current. Indeed, there is evidence of these predominant winds in Southern Mozambique where parabolic coastal dunes, blow outs and some coastal lakes indicate prevalence of SSE winds. At Pomene, fallen and dead trees along the shoreline of the Indian Ocean show ongoing erosion. This paper focuses spit development in Pomene from 1984 to 2007 in order to find the pattern of landscape change related to coastal processes.

\section{Study area}

Pomene is part of the coastal plain of Mozambique, which shows evolution related to fluctuation of sea level during the Pleistocene and Holocene, Armitage et al [2]. Coastal parabolic dunes, sand beach, estuary and mangrove compose the study area. The coastal dunes are pointing to NNW and are covered by vegetation. They partly cover the Pleistocene dunes. Mangrove surrounds the estuary sheltered from swells.

The spit of Pomene is arc shaped and concave towards Indian Ocean side and it is situated between the Indian Ocean and the estuary, fig. 1.b). It is a sand beach feature that extends towards southeast exposed to wind, forming small 
dunes. The mean spring tidal range is $\sim 3 \mathrm{~m}$ Armitage et al [2]. The beach is opened to waves of high energy.
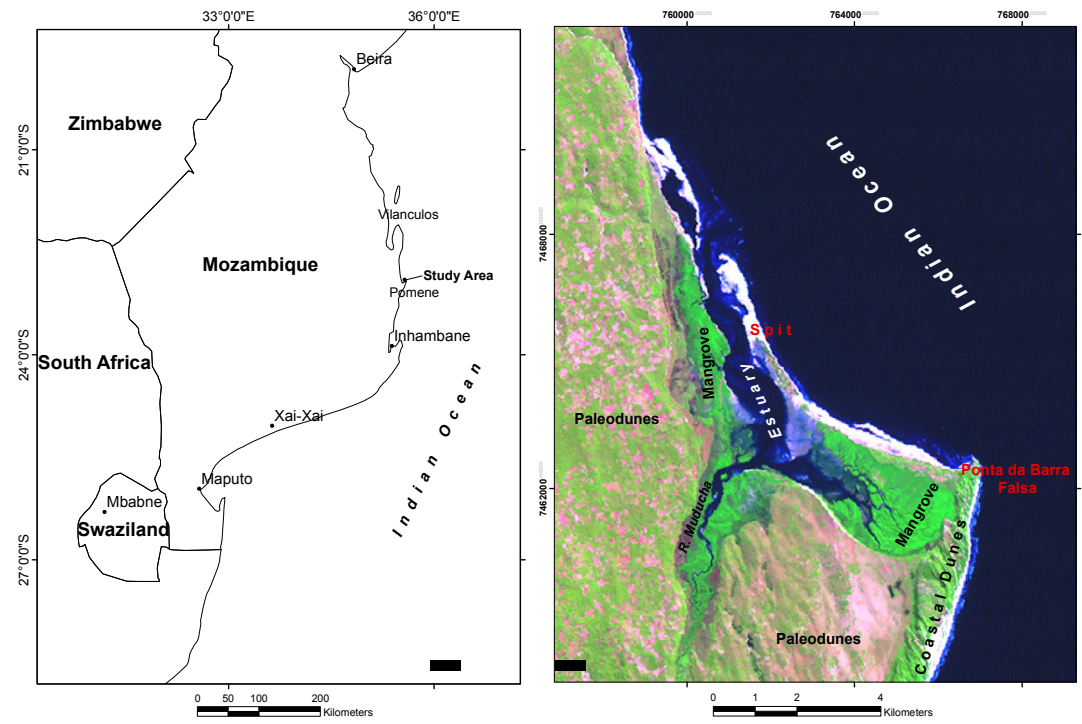

Figure 1: a) Location of the study area, and b) Landsat ETM+ image (dated 01.06.2001, UTM projection, zone 36S, WGS84) in 5-4-3 to R-G$\mathrm{B}$ band combination showing the physiographic features of Pomene.

\section{Method and data}

There are several methods that can be used to monitor landform change. One of the methods is to establish ground profiles and measure changes over a certain period of time. However, there is no baseline data at Pomene that can support such monitoring of landscape change. Instead satellite data and aerial photographs provide better possibilities for monitoring landforms, and may replace ground measurements. Aerial photographs have good spatial resolution and provide stereo capability. They are ideal to monitor geomorphologic change. However, there are few series of aerial photos covering Pomene. Thus Landsat satellite images were chosen for the study due to its capability of covering relative long temporal scale. Although Landsat images have a coarser spatial resolution $(30 \mathrm{~m})$ compared to aerial photographs, we are convinced that it will be possible to find the pattern of changes for the spit of Pomene. Similar studies using Landsat images have been performed by White and El Asmar [5] and Siddiqui and Maajid [6].

\subsection{Satellite data}

Four multi-temporal Landsat TM/ETM+ images were used, dated $3^{\text {rd }}$ December 1984, $21^{\text {st }}$ April 1989, 01 ${ }^{\text {st }}$ January 2001 and $24^{\text {th }}$ October 2007. Path/row 
166/076 covers the Pomene area. We selected the images with little cloud coverage and noise as possible. Nevertheless, the 2007 image has some gaps caused by the faulty Scan Line Corrector (SLC). According to the provider, United States Geological Survey (USGS), the SLC-off images are corrected from lost lines by the use of old images covering the same area. Thus, this does not seem to affect the final results of this study. Furthermore the gaps are less noticeable in the middle of the scene where the study area is located. Geometric and radiometric corrections were done by the USGS for all the satellite images except the scene from 1984 which was not registered perfectly to the other images.

\subsection{Geometric correction}

Geometric correction is necessary for change detection. The satellite image from 1984 has a small shift compared to the other the satellite images. Thus, we orthorectified it to match with other images, using 35 control points "image to image" with $1^{\text {st }}$ order polynomial, ending up with root mean square (R.M.S.) of less than 0.5 pixel. All images were projected to UTM zone 36S using WGS84 datum. The UTM projection uses a metric scale and is appropriate for estimating areas and distances. The images were resampled to the same pixel size $(28.5 \mathrm{~m})$ and each Landsat scene was resized (with the same dimensions and references) in order to fit the study area, aiming to avoid processing unnecessary data. All the geometric corrections performed in this study are prerequisite to the compatibility of the images for comparison purpose.

\subsection{Image classification}

Water can be isolated from land in each satellite image outlining the shoreline and the spit by threshold value in a spectral band. Wilson [7] refers to automatic segmentation of water and variance filter as a good method for water classification. Attempts to perform segmentation in a single band have shown low accuracy due to waves approaching the coast or to the tidal flat when the tide is low. The tidal flat shows relative high reflectance even using near-infrared (NIR) band. Mølle-Jensen [8] classified water using certain level of threshold in Landsat band 4 (NIR) and band 5 short-wavelength infrared (SWIR) arguing that with this approach there would be few misclassifications. Ryu et al [9] regarded the NIR (band 4 in Landsat $\mathrm{TM} / \mathrm{ETM}+$ ) as a good band for extracting water bodies such as sea water, and the SWIR (band 5 Landsat TM/ETM+) as a good band to detect moisture content, detecting the tidal flat. This approach is very useful mainly when there is no information about the tidal condition in the time the satellite image was taken, principally in mesotidal or macrotidal coasts.

Unsupervised classification (ISO DATA) into 30 classes, using red, NIR, and SWIR bands, was performed on each resized Landsat scene. The 30 classes were grouped into two classes using visual interpretation of the RGB image. This procedure resulted in one raster image for each one of the four resized satellite images used in this study, outlining the shoreline and the spit. The selection of bands to be included in classification was done according to papers mentioned 
above and histogram comparisons. The use of SWIR in this classification is an attempt to reduce the error due to tidal conditions according to Ryu et al [9]. If the satellite image is taken in low tide, the tidal flat will remain with high moisture content and will possibly be detected by SWIR and appear as a class that will be visually interpreted and grouped into the water class.

\subsection{GIS processing}

Geographic Information System (GIS) software was used to process and show different phases of spit development. There are several ways to compare physiographic changes in two or more classified raster images. We performed cross-classification using IDRISI involving two by two images belonging to the subsequent years in comparison (i.e. 1984-1989, 1989-2001 and 2001-2007). The resulting images show new classes for all combinations of categories in each pair of images included. The fewer number of classes involved in this operation, the simpler the interpretation will be. As we used only two classes, interpretation to these was relatively easy. The method involves a pixel by pixel operation and requires raster images of the same size (number of columns and number of rows) and coordinate system. This prerequisite has been satisfied by geometric correction.

The results of the cross-classification are three raster maps showing four classes including the area of change that was classified as accreted area or eroded area. For the resultant maps the spit was masked from "7,462,000.00" northing in a polygon and tabulation was carried out to quantify the area of change.

\section{Results and discussion}

The resulting maps, representing mainly the erosion and accretion over the last 23 years period (i.e., between 1984-2007) are presented in figure 2. The used method proved suitable for outlining shoreline, giving a good accuracy. The presentation mode of the results is of importance. The raster images and crossclassification process used in this work allow us to visualize area of change in the maps that enhance the changes more efficiently than a vector approach. Vector representation would call for additional interpretation to identify eroded and accreted area from one stage to the subsequent.

There is a general tendency of erosion at the eastern side of the spit and accretion at the NNW side, creating an elongation and thinning of the spit. This is seen from 1989 to 2001 ( $\sim 12$ years) and from 2001-2007 where the spit of Pomene has increased in concavity towards the Indian Ocean, fig. 2.b) and 2.c). The accretion at the western side of the spit verified from 1989 - 2001 suggests the combined effect of offshore winds and longshore currents. The offshore winds might carry enough dried sand to the western side of the spit. The estuary might play a role bringing sediments from land, which should be distributed by waves, or possibly accreting the estuarine side of the spit. However, the estuary shows low dynamic and capacity for carrying sand from inland to the sea. The mangrove surrounding the estuary is an indication of the low dynamic of the estuary. A possible mechanism for reworking the shore is the presence of tidal 
currents in the estuary given the $\sim 3 \mathrm{~m}$ of mean spring tidal range reported by Armitage et al [2]. The tidal currents are probably responsible for the distribution of sediments in western side of the spit as seen from 1984-1989 (fig. 2.a) where the estuarine side of the spit shows ongoing erosion.

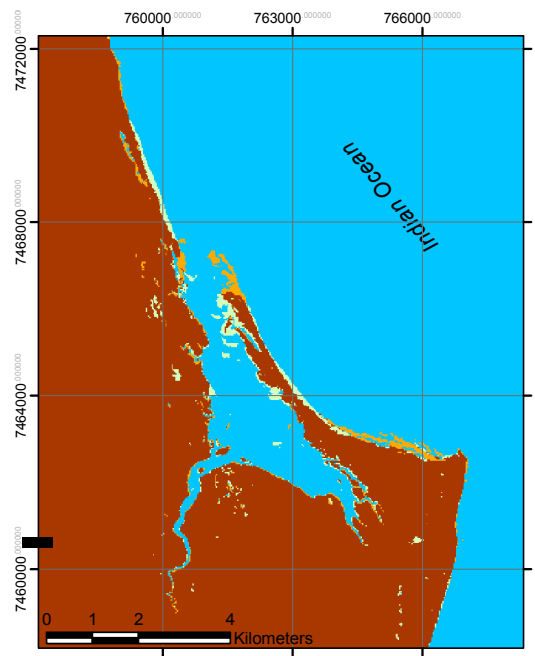

a)

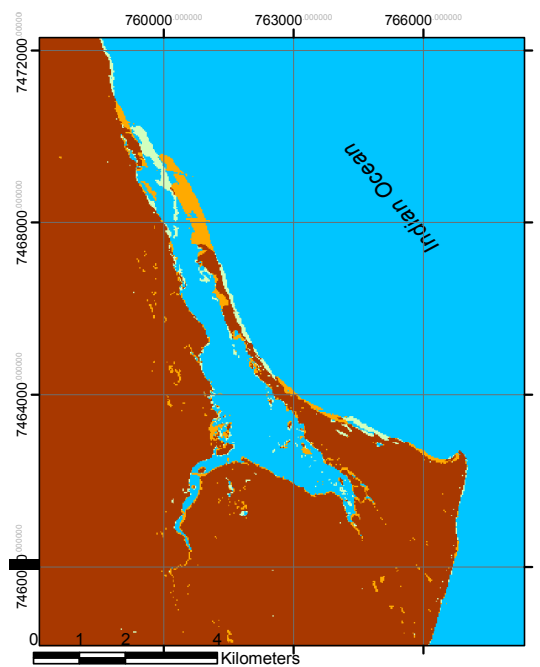

c)

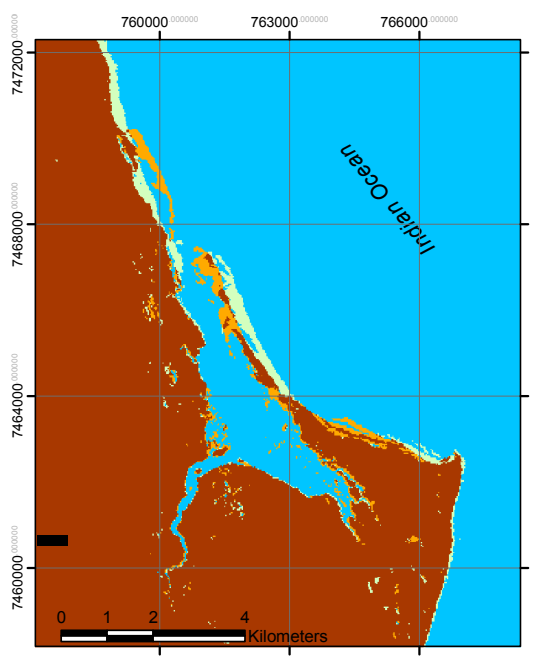

b)

\section{Legend}

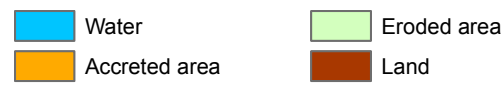

Figure 2: $\quad$ Maps of Cross-classified images showing eroded area and accreted area; a) from 1984 to 1989 , b) from 1989 to 2001 and c) from 2001 to 2007 . The maps are in WGS84 datum, UTM zone $36 \mathrm{~S}$.

Important to note here regarding the coastal processes, are parallel features immediately north of the headland (Ponta da Barra Falsa). These features are 
sequences of bars and runnels that are probably migrating to the coast and they are well pronounced in 1984-1989 cross-classified image as well as in the 19892001 cross-classified image, fig. 2.a and fig. 2.b respectively. According to Bird [10] the sequences of bars and runnels are wave dominated features parallel to the coast. The sediments composing the bars are probably coming from southern coastal dunes, carried by longshore currents and reworked by refracted waves immediately north of the headland. The southern part of the headland is composed by coastal dunes and has shown erosion in all periods by comparison, fig. 2 .

The study shows the horizontal area development of the spit and not the volume of sand that shapes this landform. However, most parts of the spit are lowland sand beach (fig. 3), which increases in height southward due to sand accumulation by wind effect.

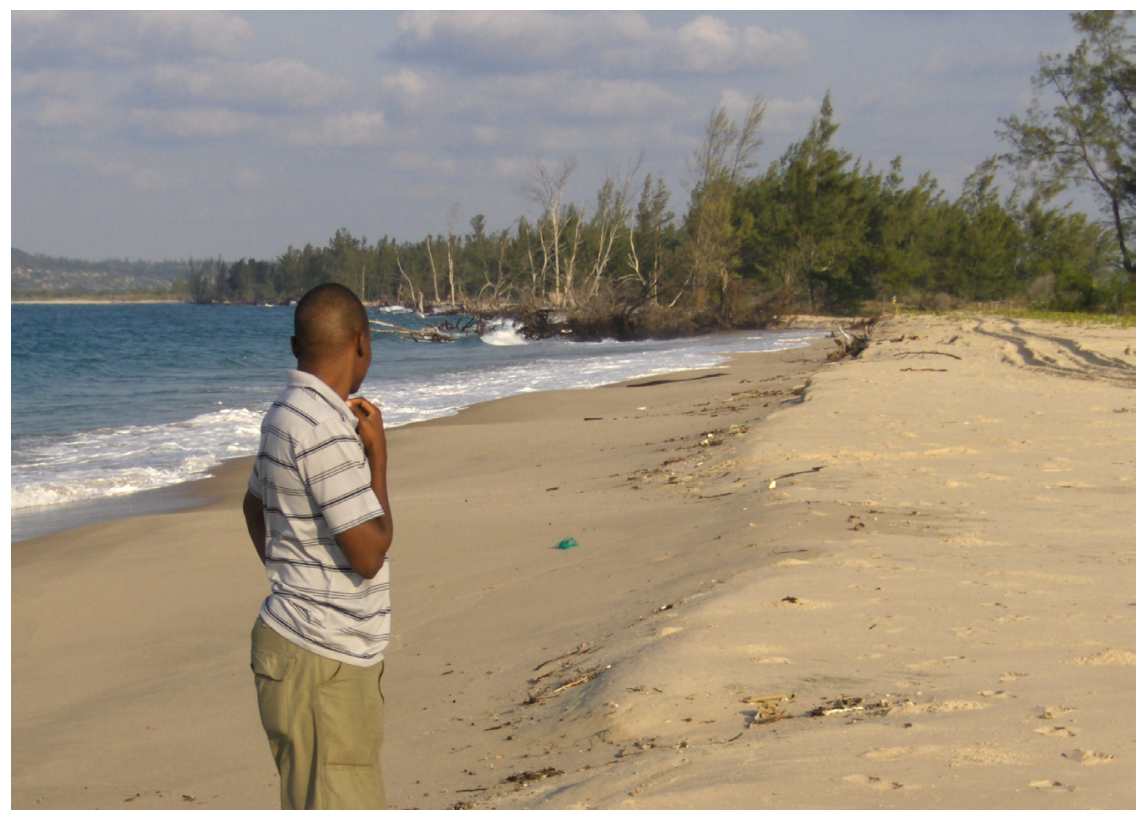

Figure 3: A view of the spit of Pomene at the Indian Ocean side (14/06/2007), showing the interaction of waves and shore. The dead trees show clearly the dynamic of this area within the last few years.

The horizontal development of the spit was tabulated using a polygon mask. The result of tabulation is the area of change of the spit and land presented by hectares, table 1.

The table 1 shows a concordance to the visual interpretation of the resulted maps in fig. 2. There is a general tendency of increasing on the accretion value over time reflecting an increasing rapid growth of the spit. The accretion is more notable than the erosion, except from 1984 to 1989. The sediments eroded in 
southern coastal dunes and in eastern side of the estuary are carried out by longshore currents and deposited in northern side of the spit.

Table 1: Tabulated area of change for the spit of Pomene, from $7,462,000.00$ northing. The area is given in Hectares (ha).

\begin{tabular}{|c|c|c|c|}
\hline Time period & Land (ha) & Accreted area (ha) & Eroded area (ha) \\
\hline $1984-1989$ & 382.81 & 67.25 & 83.82 \\
\hline $1989-2001$ & 348.54 & 127.85 & 101.53 \\
\hline $2001-2007$ & 419.12 & 134.26 & 59.05 \\
\hline
\end{tabular}

Field observations confirm erosion of the eastern side of the spit, fig. 3. The erosion process is evident by dead and fallen trees in the water and by geomorphic structures showing sand removal at the shore.

Uncertainty remains regarding the future of the spit. The lack of ground data and understanding of tidal currents at local scale is a limitation in predicting the future landscape change of the Pomene area and especially of the spit. However, according to the results of this study we believe that in the short term the spit will split at its narrowest part creating a new inlet between the estuary and the Indian Ocean. The process may continue and new accumulation may start again. The rate of changes observed will be of importance to coastal planning of the area.

\section{Conclusions}

This study has added data to the few published studies regarding the coastal geomorphology in Mozambique. Landsat images, although they have a relatively coarse spatial resolution, are very useful for monitoring the relatively rapid changes in geomorphologic features such as spit development. The unsupervised classification method, using Red, NIR and SWIR bands shows a good enough accuracy to extract the shoreline, assisting the decision to group complicated features that could not be mapped by manual digitizing using vectors. Furthermore, identifying a shoreline in raster images allow a cross-classification that clearly shows the changes (erosion/accretion) between different image pairs.

The Pomene spit is growing northward and is severely eroded at the Indian Ocean side, becoming more elongated and narrow. The spit growth towards NNW is an evidence of longshore drift caused by prevailing SSW wind as noted by Ramsay [4]. The waves, longshore currents and offshore winds are the main causes of the spit development.

\section{Acknowledgement}

This work was granted by SIDA/SAREC in a cooperation project between the Department of Geology of Eduardo Mondlane University in Mozambique and Department of Physical Geography and Quaternary Geology of Stockholm University in Sweden. The authors are also grateful to Prof. Mussa Achimo, 
from Eduardo Mondlane University and Prof. Karin Holmgren from Stockholm University for the coordination on this project.

\section{References}

[1] Cooper, J.A. \& Pilkey, O.H., The Barrier Islands of Southern Mozambique. Journal of Coastal Research 36, pp. 164-172, 2002.

[2] Armitage, S.J., Botha, G. A., Duller, G.A.T., Wintle, A. G., Rebêlo, L.P. \& Momade, F.J., The formation and evolution of the barrier islands of Inhaca and Bazaruto, Mozambique. Geomorphology, 82, pp. 295-308, 2006.

[3] Chemane, D., Motta, H. \& Achimo, M., Vulnerability of coastal resources to climate changes in Mozambique: a call for integrated coastal zone management. Coastal and Ocean Management, 37, pp. 63-83, 1997.

[4] Ramsay, P.J., Marine geology of Sodwana Bay shelf, southeast Africa. Marine Geology 120, 255-247, 1994.

[5] White, K. \& El Asmar., H.M., Monitoring changing position of coastlines using Thematic Mapper image, an example from the Nile Delta. Geomorphology 29, pp. 93-105, 1999.

[6] Siddiqui, M.N. \& Maajid, S., Monitoring of geomorphological changes for planning reclamation work in coastal area of Karachi, Pakistan. Advances in Space Research, 33, pp. 1200-1205, 2004.

[7] Wilson, P.A., Rule based classification of water in Landsat MSS images using the variance filter. Photogrammetric Engineering and Remote Sensing 63, pp. 485-491, 1997.

[8] Møller-Jensen, L., Knowledge-based classification in urban area using texture and context information in Landsat-TM image. Photogrammetric Engineering and Remote Sensing 56, pp. 899-904, 1990.

[9] Ryu, J.H., Won, J.S. \& Min, K.D., Waterline extraction from Landsat TM data in a tidal flat: A case study in Gomso Bay, Korea. Remote Sensing of Environment 83, pp. 442-456, 2002.

[10] Bird, E.C.F., Coastal Geomorphology: An Introduction. Wiley and Sons, Chichester, 2000. 